\title{
Influência da substituição parcial de cimento por cinza ultrafina da casca de arroz com elevado teor de carbono nas propriedades do concreto
}

\author{
Influence of the partial replacement of cement by \\ ultrafine rice husk ash with high-carbon content on the \\ properties of concrete
}

\section{Guilherme Chagas Cordeiro \\ Romildo Dias Toledo Filho \\ Eduardo de Moraes Rego Fairbairn}

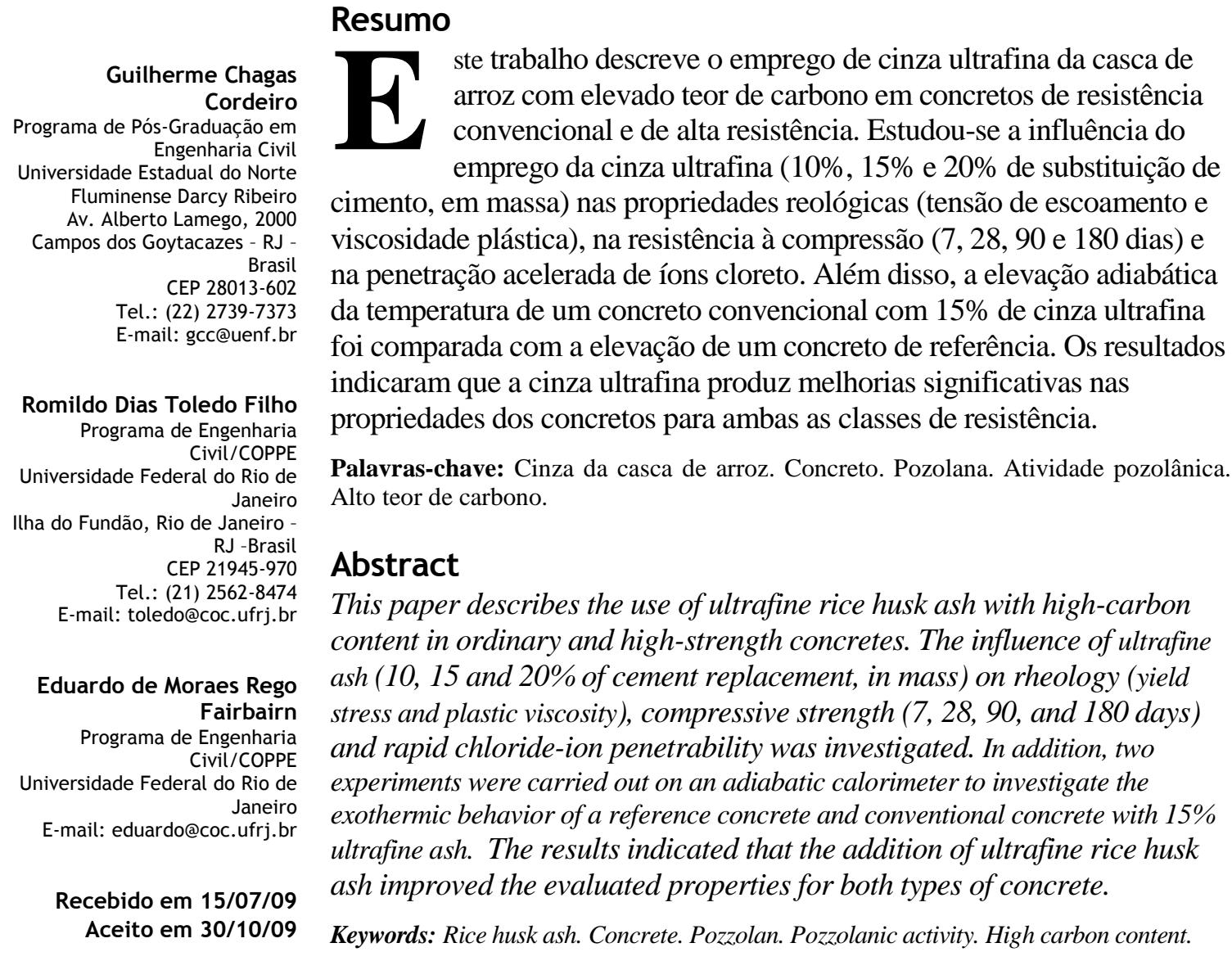




\section{Introdução}

A grande disponibilidade de cinza da casca de arroz tem motivado inúmeras pesquisas sobre sua aplicação em concretos desde a década de 1970 (HWANG; CHANDRA, 2002; JAMES; SUBBA RAO, 1986; MEHTA, 1977; ZHANG; MALHOTRA, 1996). A obtenção de produtos cimentícios contendo cinza residual da casca de arroz é uma alternativa para solucionar o problema da disposição das cinzas no meio ambiente, além de gerar um material de maior valor agregado. $\mathrm{O}$ emprego da cinza da casca de arroz tende a promover melhorias nas propriedades mecânicas (BUI; HU; STROEVEN, 2005; ZHANG; MALHOTRA, 1996) e na durabilidade de concretos (NEHDI; DUQUETTE; EL DAMATTY, 2003), além de reduzir a temperatura de hidratação (MEHTA; PIRTZ, 1978). Por outro lado, a cinza pode comprometer a trabalhabilidade do concreto em razão da elevada superfície específica de suas partículas e, em alguns casos, do alto teor de carbono remanescente após a queima da casca.

Vários estudos foram conduzidos com o intuito de determinar as condições de queima mais adequadas para a produção de cinza da casca de arroz com alta reatividade (JAMES; SUBBA RAO, 1986; HANAFI et al., 1980; MEHTA; PITT, 1976; SUGITA, 1994). Fatores associados à queima da casca de arroz, como temperatura, taxa de aquecimento, tempo de residência e ambiente, determinam o teor de sílica, a estrutura da sílica, a superfície específica e a quantidade de impurezas na pozolana, o que influencia sobremaneira sua reatividade. Assim, é possível produzir cinzas da casca de arroz com teores de sílica amorfa acima de $95 \%$ e superfícies específicas em torno de $40.000 \mathrm{~m}^{2} / \mathrm{kg}$, o que confere ao material elevada atividade pozolânica. Contudo, as condições adequadas de queima obtidas em laboratório são, por vezes, extremamente difíceis de obter em larga escala, sobretudo em caldeiras convencionais, como as utilizadas em grande parte das unidades de beneficiamento de arroz. Assim, percebe-se uma grande discrepância ao se compararem as propriedades de cinzas produzidas em laboratório e do material residual proveniente da indústria. Além disso, a falta de homogeneidade, principalmente no que se refere ao tamanho de partículas e ao teor de carbono, compromete sua comercialização como pozolana (MALHOTRA; MEHTA, 1996).

Nesse escopo, este trabalho visa estudar o uso em concreto de uma cinza ultrafina da casca de arroz produzida a partir de um subproduto com alto teor de carbono (12\%). Nesse caso, utilizou-se uma moagem ultrafina em moinho vibratório para conferir maior homogeneidade à cinza. $\mathrm{O}$ potencial da cinza ultrafina foi avaliado com o emprego de diferentes teores de substituição de cimento Portland $(0 \%, 10 \%, 15 \%$ e $20 \%$ em massa) em concretos de resistência convencional $(25 \mathrm{MPa})$ e de alta resistência (60 MPa). Estes foram avaliados quanto à reologia (ensaios em reômetro BTRHEOM), resistência à compressão e penetração acelerada de íons cloreto. Por fim, comparou-se a elevação adiabática da temperatura de um concreto de resistência convencional com $15 \%$ de cinza ultrafina da casca de arroz com a elevação de um concreto de referência $(100 \%$ de cimento Portland).

\section{Materiais e métodos}

A cinza residual utilizada como matéria-prima foi coletada em uma unidade de beneficiamento de arroz, localizada no município de Jaraguá do Sul, SC. Não houve controle das condições de queima da casca de arroz. Contudo, a presença de sílica cristalina, sob a forma de cristobalita, ilustrada na Figura 1 , indica que temperaturas acima de $800{ }^{\circ} \mathrm{C}$ foram provavelmente alcançadas (HAMAD; KHATTAB, 1981). Cominuiu-se a cinza residual em um moinho vibratório (Aulmann \& Beckschulte Maschininfabrik) com vaso cilíndrico (diâmetro interno de $19 \mathrm{~cm}$ ) de aço de $33 \mathrm{~L}$. A cada batelada foram utilizados $16,5 \mathrm{~L}$ de corpos moedores cilíndricos (diâmetro $13 \mathrm{~mm}$ e altura 13 $\mathrm{mm}$ ) de alumina e $8 \mathrm{~L}$ de amostra. O tempo de moagem, otimizado com base no consumo de energia e nos valores de atividade pozolânica da cinza, foi de $120 \mathrm{~min}$ (CORDEIRO et al., 2009). As condições de moagem adotadas possibilitam a redução das partículas para um tamanho médio inferior a $10 \mu \mathrm{m}$, com demanda energética da ordem de $100 \mathrm{kWh} / \mathrm{t}$ (CORDEIRO, 2006).

As Tabelas 1 e 2 apresentam, respectivamente, a composição química e as principais características físicas da cinza ultrafina da casca de arroz. A composição química foi determinada por fluorescência de raios $\mathrm{X}$ (espectrômetro Phillips PW 2400). Determinou-se a perda ao fogo de acordo com os procedimentos prescritos na norma brasileira NBR 5743 (1989). A distribuição de tamanho das cinzas foi obtida por meio de analisador de partículas a laser Mastersizer 2000, Malvern Instruments. Obteve-se a superfície específica da amostra por adsorção de nitrogênio (método BET) em equipamento Gemini 2375 V5. A massa específica foi determinada em picnômetro a gás (He), modelo Accupyc da Micromeritics. A 
atividade pozolânica neste trabalho foi determinada por duas metodologias distintas: índice de atividade pozolânica com cimento Portland (NBR 5752:1992) e Chapelle Modificado (RAVERDY et al., 1980) - baseado na fixação de $\mathrm{CaO}$ pela cinza. Pelos resultados, é importante destacar o elevado teor de carbono e atividade pozolânica, o reduzido tamanho de partículas e a elevada atividade pozolânica da cinza ultrafina.

Para a produção dos concretos utilizaram-se cimento Portland sem adição mineral (cimento para poços petrolíferos CPP Classe $\mathrm{G}$ - NBR
9831:1993), agregado graúdo com dimensão máxima nominal de $19 \mathrm{~mm}$, areia quartzosa de rio (módulo de finura de 2,12), aditivo superplastificante com base em cadeia de éter carboxílico (solução aquosa com 32,6\% de sólidos) e água deionizada. A Tabela 1 apresenta a composição química do cimento Portland, determinada por espectroscopia de fluorescência de raios $\mathrm{X}$. A Tabela 2 apresenta as principais propriedades físicas do cimento.

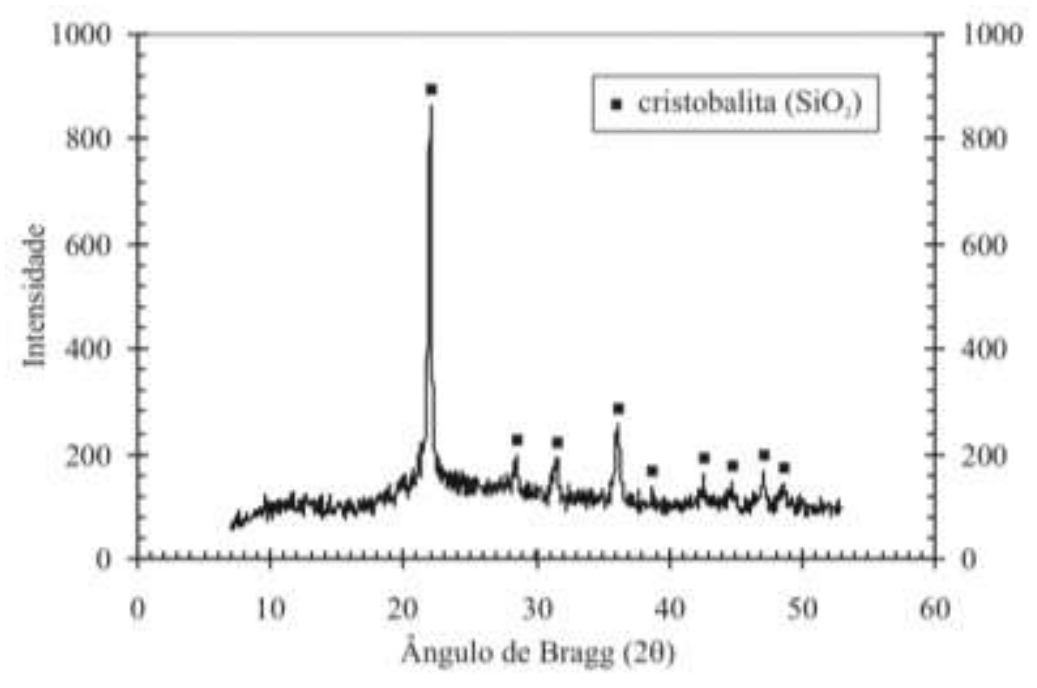

Figura 1 - Difratograma de raios X da cinza da casca de arroz - difratômetro Rigaku Miniflex com tubo de Cu-Ka

\begin{tabular}{c|c|c|c|c|c|c|c|c}
\hline Composto & $\mathbf{S i O}_{\mathbf{2}}$ & $\mathrm{Al}_{\mathbf{2}} \mathbf{O}_{\mathbf{3}}$ & $\mathbf{F e}_{\mathbf{2}} \mathbf{O}_{\mathbf{3}}$ & $\mathbf{C a O}$ & $\mathbf{N a}_{\mathbf{2}} \mathbf{O}$ & $\mathbf{K}_{\mathbf{2}} \mathbf{O}$ & $\mathbf{S O}_{\mathbf{3}}$ & $\begin{array}{c}\text { Perda } \\
\text { ao fogo }\end{array}$ \\
\hline Cinza residual & 82,62 & 0,38 & 0,49 & 0,85 & 0,05 & 1,81 & 0,06 & 11,88 \\
\hline Cimento Portland & 20,85 & 4,23 & 5,25 & 63,49 & 0,16 & 0,40 & 2,38 & 1,05 \\
\hline
\end{tabular}

Tabela 1 - Composição química (\%) da cinza da casca de arroz e do cimento Portland

\begin{tabular}{c|c|c}
\hline Característica (unidade) & $\begin{array}{c}\text { Cinza da casca } \\
\text { de arroz }\end{array}$ & $\begin{array}{c}\text { Cimento } \\
\text { Portland }\end{array}$ \\
\hline Tamanho médio de partícula $(\mu \mathrm{m})$ & 6,8 & 16,9 \\
\hline Percentual maior que $45 \mu \mathrm{m}$ & 0 & 8,4 \\
\hline Superfície específica $\left(\mathrm{m}^{2} / \mathrm{kg}\right)$ & $33.672^{1}$ & $308^{2}$ \\
\hline Massa específica $\left(\mathrm{kg} / \mathrm{m}^{3}\right)$ & 2.293 & 3.170 \\
\hline Índice de atividade pozolânica $(\%)$ & 109 & - \\
\hline Atividade química $(\mathrm{mg} \mathrm{CaO} / \mathrm{g})$ & 736 & - \\
\hline
\end{tabular}

${ }^{1}$ Superfície específica B.E.T.

${ }^{2}$ superfície específica Blaine

Tabela 2 - Características da cinza ultrafina da casca de arroz e do cimento Portland 
A dosagem dos concretos foi realizada com o auxílio do programa computacional Betonlab Pro2 (SEDRAN; DE LARRARD, 2000), que possibilita a simulação numérica de diferentes composições para a seleção adequada dos materiais com base no Modelo de Empacotamento Compressível, proposto por De Larrard (1999). Os valores de resistência à compressão dos concretos de referência foram estipulados em $25 \mathrm{MPa}$ e 60 $\mathrm{MPa}$, e a consistência, de acordo com ensaio de abatimento do tronco de cone, foi mantida na faixa entre $130 \mathrm{~mm}$ e $170 \mathrm{~mm}$, com teores específicos de aditivo superplastificante. Foram dosadas quatro misturas para cada classe de resistência: referência e concretos com substituição de $10 \%, 15 \%$ e $20 \%$ (em massa) de cimento Portland por cinza ultrafina da casca de arroz, conforme mostram as Tabelas 3 e 4. Como as massas específicas do cimento Portland e da cinza ultrafina são diferentes, a correção nos valores de massa de material por metro cúbico de concreto foi feito com a redução proporcional da massa de agregados. Dessa forma, o volume de material aglomerante (cimento e cinza ultrafina) é maior nos concretos com cinza em comparação com as misturas de referência, o que representa uma vantagem adicional desse tipo de aplicação.

Além do ensaio de abatimento, a caracterização dos concretos no estado fresco foi realizada pela determinação da tensão cisalhante de escoamento $\left(\tau_{0}\right)$ e viscosidade plástica $(\mu)$ com emprego do reômetro BTRHEOM (DE LARRARD et al., 1997), Figura 2a, após 10 min da etapa de mistura dos concretos em betoneira. Admitiu-se, neste trabalho, que os concretos comportaram-se como fluidos de Bingham. A resistência à compressão dos concretos foi determinada pela ruptura de corpos-de-prova cilíndricos (100 mm de diâmetro e $200 \mathrm{~mm}$ de altura) em prensa servo-controlada Shimadzu UH-F1000kNI, após 7, 28, 90 e 180 dias de cura em câmara úmida (temperatura de $21^{\circ} \mathrm{C}$ e umidade relativa de $100 \%$ ). Os ensaios foram conduzidos de acordo com a NBR 5739:1994, com velocidade de $0,0075 \mathrm{~mm} / \mathrm{min}$, e foram utilizados quatro corpos-de-prova para cada idade. Investigou-se o comportamento dos concretos com vistas à durabilidade em ensaios de penetração acelerada de íons cloreto aos 28 dias, de acordo com as prescrições normativas da ASTM C1202 (2002). Nesse caso, os testes foram feitos em duplicata. Além disso, realizaram-se dois testes em um calorímetro adiabático (Figura 2b) para investigar o comportamento exotérmico dos concretos de resistência convencional de referência e com $15 \%$ de cinza ultrafina da casca de arroz. Os testes foram conduzidos em um corpo-de-prova de 200 L até 500 horas de hidratação.

\begin{tabular}{c|c|c|c|c|c|c|c}
\hline \multirow{2}{*}{ Misturas } & \multicolumn{7}{c}{ Materiais $\left(\mathbf{k g} / \mathbf{m}^{\mathbf{3}}\right)$} \\
\cline { 2 - 8 } & $\begin{array}{c}\text { Cimento } \\
\text { Portland }\end{array}$ & $\begin{array}{c}\text { Cinza } \\
\text { ultrafina }\end{array}$ & $\begin{array}{c}\text { Agregado } \\
\text { miúdo }\end{array}$ & $\begin{array}{c}\text { Agregado } \\
\text { graúdo }\end{array}$ & Água & \multirow{2}{*}{ SP* $^{*}$} \\
\hline \multicolumn{2}{c|}{ Referência } & 365,9 & - & 724,7 & 1001,0 & 220,3 & - \\
\hline \multirow{2}{*}{$\begin{array}{c}\text { Cinza } \\
\text { ultrafina } \\
\text { da casca } \\
\text { de arroz }\end{array}$} & $10 \%$ & 329,3 & 36,6 & 724,0 & 999,9 & 220,3 & 0,36 \\
\cline { 2 - 8 } & $15 \%$ & 311,0 & 54,9 & 723,9 & 999,6 & 220,3 & 0,43 \\
\hline
\end{tabular}

" SP: aditivo superplastificante, cujo valor se refere à massa da fração sólida.

Tabela 3 - Composição dos concretos de resistência convencional

\begin{tabular}{c|c|c|c|c|c|c|c}
\hline \multirow{2}{*}{ Misturas } & \multicolumn{7}{c}{ Materiais $\left(\mathbf{k g} / \mathbf{m}^{\mathbf{3}}\right)$} \\
\cline { 2 - 8 } & $\begin{array}{c}\text { Cimento } \\
\text { Portland }\end{array}$ & $\begin{array}{c}\text { Cinza } \\
\text { ultrafina }\end{array}$ & $\begin{array}{c}\text { Agregado } \\
\text { miúdo }\end{array}$ & $\begin{array}{c}\text { Agregado } \\
\text { graúdo }\end{array}$ & Água & \multirow{2}{*}{$\mathbf{S P}^{*}$} \\
\hline \multicolumn{2}{c|}{ Referência } & 478,0 & - & 905,3 & 860,0 & 164,4 & 1,43 \\
\hline \multirow{2}{*}{$\begin{array}{c}\text { Cinza } \\
\text { ultrafina } \\
\text { da casca } \\
\text { de arroz }\end{array}$} & $10 \%$ & 430,2 & 47,8 & 904,1 & 858,8 & 164,4 & 1,91 \\
\cline { 2 - 8 } & $15 \%$ & 406,3 & 71,7 & 903,4 & 858,1 & 164,4 & 2,20 \\
\hline
\end{tabular}

"SP: aditivo superplastificante, cujo valor se refere à massa da fração sólida.

Tabela 4 - Composição dos concretos de alta resistência 


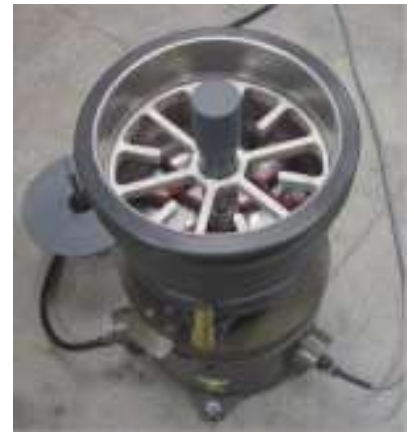

(a)

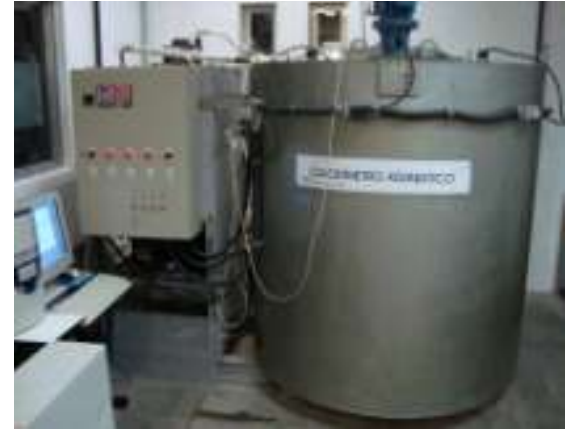

(b)

Figura 2 - Reômetro BTRHEOM (a) e calorímetro adiabático do Laboratório de Estruturas da COPPE/UFRJ (b)

\section{Resultados}

A substituição de parte do cimento Portland pela cinza ultrafina da casca de arroz reduz os valores de abatimento do tronco de cone em decorrência da elevada superfície específica da cinza e do alto teor de carbono, como pode ser observado na Tabela 5 - abatimento inicial. Com isso, fez-se necessário emprego de teores específicos de aditivo superplastificante (vide Tabelas 3 e 4) para a manutenção dos valores de abatimento do tronco de cone na faixa estabelecida (Tabela 5 abatimento final). Após a equiparação da consistência, foram realizados ensaios no reômetro BTRHEOM. A Tabela 5 também apresenta os valores de $\tau_{0}$ e $\mu$, obtidos com o modelo de Bingham, que é adequado para os concretos na faixa de consistência utilizada (CORDEIRO; TOLEDO FILHO; FAIRBAIRN, 2008; DE LARRARD, 1999). Para ambas as classes de resistência verifica-se uma diminuição acentuada dos valores de $\tau_{0}$, sem segregação, após a incorporação da cinza ultrafina da casca de arroz, fenômeno que pode ser atribuído ao efeito lubrificante proporcionado pelo aditivo superplastificante. Para o parâmetro $\mu$, a redução em função da incorporação da cinza é menos expressiva. Quanto ao teor de cinza ultrafina na mistura, não são verificadas grandes variações nos valores de $\tau_{0}$ e $\mu$. É importante destacar que um concreto com facilidade para o bombeamento $\mathrm{e}$ com consistência satisfatória apresenta, em geral, valores de viscosidade plástica inferiores a 300 Pa.s (DE LARRARD, 1999).

A substituição de cimento pela cinza ultrafina da casca de arroz proporciona incrementos nos valores de resistência à compressão do concreto de resistência convencional, principalmente nas idades mais avançadas (Tabela 6). Os teores de substituição de cimento por cinza ultrafina de $15 \%$ e $20 \%$ apresentam os melhores resultados e são estatisticamente superiores aos demais em todas as idades avaliadas, porém sem diferenças significativas entre si, de acordo com Análise de Variância e teste de Duncan $(\mathrm{p}<0,05)$ (GOMES, 1990). O teor de substituição de $10 \%$ apresenta comportamento intermediário entre a mistura de referência e as demais. As taxas de aumento da resistência à compressão no tempo, para os distintos concretos, não apresentam diferenças expressivas entre si. Há de se ressaltar o valor de resistência alcançado pelo concreto com $20 \%$ de cinza aos 180 dias (40,76 MPa), que é cerca de $23 \%$ superior ao alcançado pela referência.

No caso dos concretos de alta resistência, os valores de resistência à compressão das quatro misturas não apresentam diferenças significativas nos ensaios realizados após 7 dias de cura. Nas demais idades avaliadas, os ganhos de resistência são menos expressivos do que os obtidos para o concreto convencional, e a mistura com $20 \%$ de cinza ultrafina apresenta resistência estatisticamente superior às demais. Aos 90 e 180 dias, não há diferenças entre os valores de resistência dos concretos com $10 \%$ de cinza e de referência (teste de Duncan, $\mathrm{p}<0,05$ ). O mesmo ocorre para os concretos com $10 \%$ e $15 \%$ de cinza. $O$ teste de Duncan revela, entretanto, que as misturas de referência e com $15 \%$ de cinza ultrafina não são estatisticamente iguais.

É importante notar que, após 28 dias de cura, os concretos com $20 \%$ de cinza ultrafina alcançam valores de resistência superiores a $80 \%$ da resistência obtida aos 180 dias. Esse fato sugere que as reações pozolânicas da cinza ultrafina da casca de arroz utilizada neste trabalho contribuem de forma mais expressiva para a resistência à compressão dos concretos nos 28 dias iniciais de cura. Também é oportuno destacar as similaridades entre esses resultados e os obtidos por Zhang e Malhotra (1996). Os autores atribuíram o comportamento superior na compressão à redução da porosidade, da quantidade de portlandita e da espessura da zona de transição pasta/agregado. 


\begin{tabular}{|c|c|c|c|c|c|c|c|c|}
\hline \multirow{3}{*}{ Característica } & \multicolumn{4}{|c|}{ Concreto convencional } & \multicolumn{4}{|c|}{ Concreto de alta resistência } \\
\hline & \multirow{2}{*}{ Referência } & \multicolumn{3}{|c|}{ Cinza ultrafina } & \multirow{2}{*}{ Referência } & \multicolumn{3}{|c|}{ Cinza ultrafina } \\
\hline & & $10 \%$ & $15 \%$ & $20 \%$ & & $10 \%$ & $15 \%$ & $20 \%$ \\
\hline $\begin{array}{l}\text { Abatimento } \\
\text { inicial (mm) }\end{array}$ & 140 & 100 & 80 & 50 & 130 & 100 & 60 & 20 \\
\hline $\begin{array}{l}\text { Abatimento final } \\
\qquad(\mathrm{mm})\end{array}$ & 140 & 150 & 160 & 160 & 130 & 170 & 160 & 170 \\
\hline$\tau_{0}(\mathbf{P a})$ & 901 & 351 & 339 & 436 & 693 & 296 & 304 & 285 \\
\hline$\mu$ (Pa.s) & 54 & 64 & 63 & 55 & 306 & 235 & 268 & 250 \\
\hline
\end{tabular}

Tabela 5 - Parâmetros reológicos dos concretos com cinza ultrafina da casca de arroz

\begin{tabular}{|c|c|c|c|c|c|c|}
\hline & \multirow{2}{*}{\multicolumn{2}{|c|}{ Mistura }} & \multicolumn{4}{|c|}{ Resistência à compressão (MPa) - Coeficiente de variação $(\%)$} \\
\hline & & & 7 dias & 28 dias & 90 dias & 180 dias \\
\hline \multirow{4}{*}{ 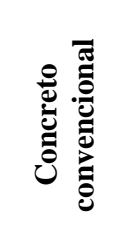 } & \multicolumn{2}{|c|}{ Referência } & $17,3( \pm 3,6)$ & $24,0( \pm 4,7)$ & $30,9( \pm 3,6)$ & $33,0( \pm 3,0)$ \\
\hline & \multirow{3}{*}{ 丞 } & $10 \%$ & $21,7( \pm 2,9)$ & $29,0( \pm 3,3)$ & $35,3( \pm 2,0)$ & $37,5( \pm 0,8)$ \\
\hline & & $15 \%$ & $24,5( \pm 2,6)$ & $32,6( \pm 2,7)$ & $38,6( \pm 1,4)$ & $40,3( \pm 4,3)$ \\
\hline & & $20 \%$ & $24,2( \pm 2,3)$ & $32,6( \pm 2,0)$ & $38,6( \pm 2,3)$ & $40,8( \pm 4,8)$ \\
\hline \multirow{4}{*}{ 롤 } & \multicolumn{2}{|c|}{ Referência } & $53,9( \pm 2,1)$ & $60,9( \pm 2,8)$ & $68,7( \pm 1,6)$ & $71,2( \pm 0,3)$ \\
\hline & \multirow{3}{*}{ 递 } & $10 \%$ & $52,5( \pm 0,4)$ & $61,0( \pm 2,4)$ & $70,0( \pm 2,0)$ & $72,5( \pm 2,6)$ \\
\hline & & $15 \%$ & $52,8( \pm 2,5)$ & $63,4( \pm 1,3)$ & $71,5( \pm 0,6)$ & $73,4( \pm 1,5)$ \\
\hline & & $20 \%$ & $54,5( \pm 1,0)$ & $70,0( \pm 0,4)$ & $74,2( \pm 1,7)$ & $76,2( \pm 1,2)$ \\
\hline
\end{tabular}

Tabela 6 - Resultados de ensaios de resistência à compressão aos 7, 28, 90 e 180 dias dos concretos com cinza ultrafina da casca de arroz com os respectivos coeficientes de variação (entre parênteses)

Com relação à penetração acelerada de íons cloreto, a cinza ultrafina da casca de arroz proporciona reduções muito pronunciadas nos valores de carga elétrica total passante, tanto para os concretos convencionais quanto para os de alta resistência, como pode ser observado na Figura 3. Para os concretos convencionais, a mistura de referência é classificada como de "alta" penetração (8.451 C), enquanto os concretos com a cinza ultrafina apresentam "baixa" penetração, com valores de carga elétrica inferiores a $2.000 \mathrm{C}$. O melhor comportamento é verificado para o concreto com $20 \%$ de cinza, o qual apresenta carga elétrica $(1.026 \mathrm{C})$, próxima ao limite entre as classes de "baixa" e "muito baixa" penetração iônica. O emprego da cinza nos concretos de alta resistência possibilita a obtenção de concretos com "muito baixa" penetração, em contraste com a mistura de referência ("baixa" penetração). A redução dos valores de carga elétrica pode ser atribuída à densificação da microestrutura dos concretos proporcionada pelas reações pozolânicas da cinza da casca de arroz em conjunto com o efeito fíler de suas partículas diminutas. Além disso, os teores mais elevados de aditivo superplastificante, empregados nas misturas com cinza da casca de arroz, podem proporcionar um melhor adensamento aos concretos, o que poderia contribuir para o refinamento dos poros. A melhoria promovida pela cinza da casca de arroz à penetração iônica acelerada observada neste trabalho é similar à constatada por Nehdi, Duquette e Damatty (2003). 


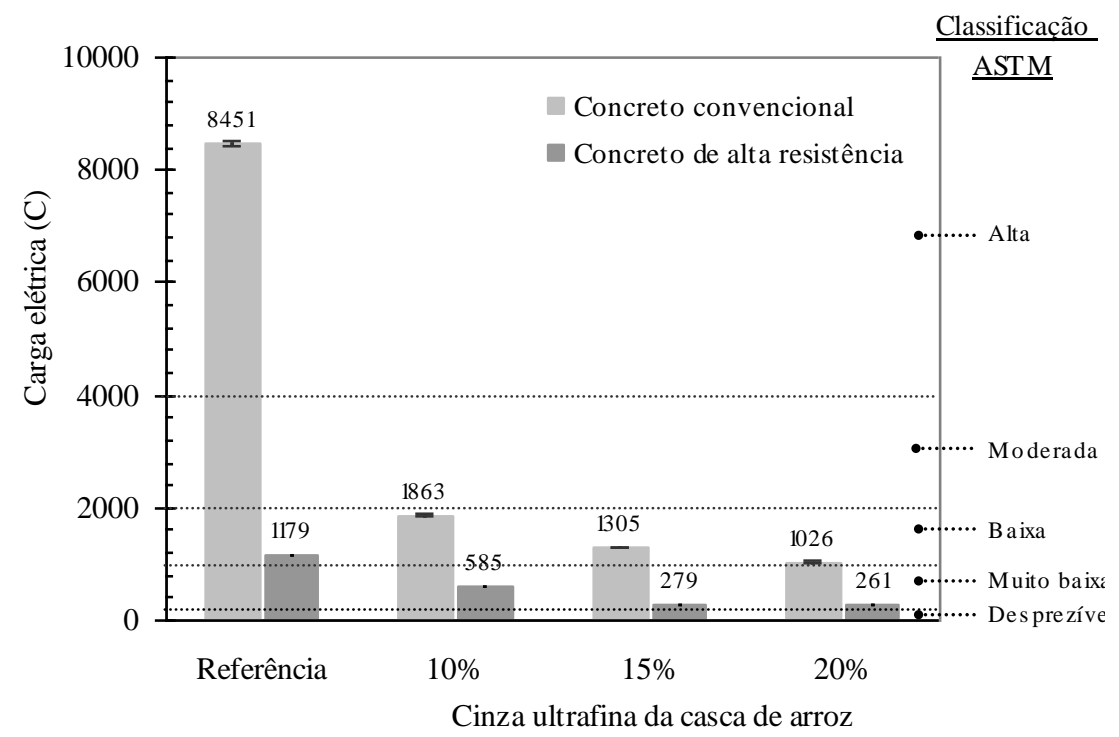

Figura 3 - Valores de penetração acelerada de íons dos concretos com cinza ultrafina da casca de arroz

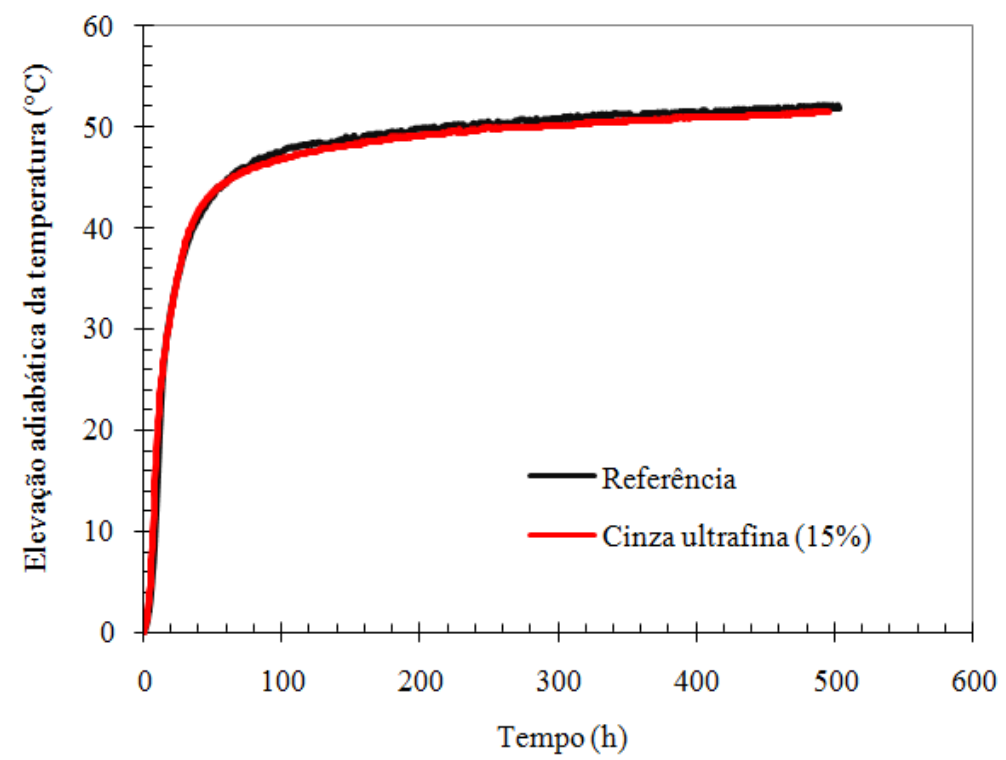

Figura 4 - Curvas de elevação adiabática da temperatura dos concretos de referência e com $15 \%$ da cinza ultrafina da casca de arroz

A Figura 4 mostra os resultados dos ensaios de elevação adiabática da temperatura conduzidos nos concretos de resistência convencional de referência e com $15 \%$ de cinza ultrafina da casca de arroz. Normalmente, a substituição de uma parcela de cimento por aditivo mineral acarreta redução do calor de hidratação como decorrência da diluição do cimento Portland (CORDEIRO, TOLEDO FILHO; FAIRBAIRN, 2008; MEHTA; PIRTZ, 1978). Para a cinza ultrafina da casca de arroz investigada neste trabalho, no entanto, esse comportamento não é observado. A comparação entre as curvas de elevação revela que a substituição de cimento pela cinza ultrafina não produz modificações quanto à quantidade de calor liberado pelos concretos. A diferença entre os valores de elevação da temperatura é igual a apenas $0,6{ }^{\circ} \mathrm{C}$ após 500 horas de ensaio. Os coeficientes de elevação adiabática, iguais a 0,142 ${ }^{\circ} \mathrm{C} . \mathrm{m}^{3} / \mathrm{kg}$ e $0,141{ }^{\circ} \mathrm{C} . \mathrm{m}^{3} / \mathrm{kg}$ para os concretos de referência e com $15 \%$ de cinza ultrafina da casca de arroz, respectivamente, não apresentam diferenças expressivas entre si. A elevada atividade pozolânica da cinza ultrafina, comprovada nos ensaios de pozolanicidade (Tabela 2) e de resistência à compressão dos concretos (Tabela 6), contribui para esse comportamento, uma vez que as reações 
pozolânicas são também exotérmicas (WALLER, 1999).

\section{Conclusões}

De acordo com os resultados apresentados, é possível concluir que:

(a) os procedimentos de moagem ultrafina adotados possibilitam a produção de cinza da casca de arroz com índice de atividade pozolânica igual a 109\% e atividade Chapelle de 736 mg/g a partir de um resíduo parcialmente amorfo e com elevado teor de carbono em sua composição;

(b) com a cinza ultrafina da casca de arroz é possível a produção de concretos com redução dos parâmetros reológicos de Bingham $\tau_{0}$ e $\mu$, desde que a consistência dos concretos seja corrigida previamente com teores específicos de aditivo superplastificante;

(c) o emprego da cinza residual em substituição ao cimento Portland, até o teor de $20 \%$,

proporciona incrementos significativos nos valores de resistência à compressão, tanto para os concretos de resistência convencional quanto para os de alta resistência. Nesse aspecto, os concretos com $20 \%$ de cinza ultrafina apresentam os maiores valores de resistência após 180 dias de cura. Cabe ressaltar que os concretos com cinza apresentam maior volume de material aglomerante em comparação com as misturas de referência;

(d) com relação à penetração acelerada de íons cloreto, o uso de cinza residual ultrafina possibilita mudanças qualitativas na classificação dos concretos segundo a ASTM C 1202 (1997). O concreto convencional muda de "alta" para "baixa" penetração de íons cloro em decorrência do uso de cinza ultrafina, enquanto, para o concreto de alta resistência, a mudança é de "baixa" para "muito baixa" penetração de íons cloreto; e

(e) no que se refere ao ensaio de calorimetria, o emprego de $15 \%$ de cinza ultrafina no concreto convencional não proporcionou alteração na temperatura de elevação adiabática, o que indica a elevada reatividade da cinza estudada.

\section{Referências bibliográficas}

\section{AMERICAN SOCIETY FOR TESTING AND} MATERIALS (ASTM). ASTM C1202: standard test method for electrical indication of concrete's ability to resist chloride ion penetration. Filadelfia, 2002.
ASSOCIAÇÃO BRASILEIRA DE NORMAS TÉCNICAS. NBR 5743: determinação da perda ao fogo. Rio de Janeiro, 1989.

\section{ASSOCIAÇÃO BRASILEIRA DE NORMAS}

TÉCNICAS. NBR 5752: materiais pozolânicos: determinação da atividade pozolânica com cimento Portland: índice de atividade pozolânica com cimento. Rio de Janeiro, 1992.

\section{ASSOCIAÇÃO BRASILEIRA DE NORMAS \\ TÉCNICAS. NBR 9831: cimento Portland} destinado à cimentação de poços petrolíferos. Rio de Janeiro, 1993.

\section{ASSOCIAÇÃO BRASILEIRA DE NORMAS TÉCNICAS. NBR 5739: concreto: ensaio de} compressão de corpos-de-prova cilíndricos. Rio de Janeiro, 1994.

BUI, D. D.; HU, J.; STROEVEN, P. Particle size effect on the strength of rice husk ash blended gapgraded Portland cement concrete. Cement and Concrete Composites, v. 27, n. 3, p. 357-366, 2005.

CORDEIRO, G. C. Utilização de cinzas ultrafinas do bagaço de cana-de-açúcar e da casca de arroz como aditivos minerais em concreto. 2006. 445 f. Tese (Doutorado em Engenharia Civil) - COPPE, Universidade Federal do Rio de Janeiro, Rio de Janeiro, 2006.

CORDEIRO, G. C.; TOLEDO FILHO, R. D.; FAIRBAIRN, E. M. R. Use of Ultra-Fine Sugar Cane Bagasse Ash as Mineral Admixture for Concrete. ACI Materials Journal, v. 105, n. 5, p. 487-493, 2008.

CORDEIRO, G. C. et al. Ultrafine Grinding of Sugar Cane Bagasse Ash for Application as Pozzolanic Admixture in Concrete. Cement and Concrete Research, v. 39, n. 2, p. 10-115, 2009.

DE LARRARD, F. Concrete mixture proportioning: a scientific approach. London: E\&FN Spon, 1999.

DE LARRARD, F. et al. New Rheometer for Softto-Fluid Fresh Concrete. ACI Materials Journal, v. 94, n. 3, p. 234-243, 1997.

\section{GOMES, F. P. Curso de Estatística}

Experimental. Piracicaba: Nobel; USP, 1990.

HAMAD, M. A.; KHATTAB, I. A. Effect of the Combustion Process on the Structure of Rice Hull Silica. Thermochimica Acta, v. 48, n. 3, p. 343349, 1981. 
HANAFI, S. et al. Surface Properties of Silicas Produced by Thermal Treatment of Rice-Husk Ash. Thermochimica Acta, v. 37, n. 2, p. 137143, 1980.

HWANG, C. L.; CHANDRA, S. The Use of Rice Husk Ash in Concrete. In: CHANDRA, S. (Ed.).

Waste Materials Used in Concrete

Manufacturing. Delhi: Standard Publishers

Distributors, 2002. p. 184-234.

JAMES, J.; SUBBA RAO, M. Reactivity of Rice Husk Ash. Cement and Concrete Research, v. 16, n. 3, p. 296-302, 1986.

MAlHOTRA, V. M.; MEHTA, P. K. Pozzolanic and Cementitious Materials. Amsterdam: Gordon and Breach Publishers, 1996.

MEHTA, P. K. Properties of Blended Cements Made from Rice Husk Ash. ACI Journal, v. 74, n. 40, p. 440-442, 1977.

MEHTA, P. K.; PIRTZ, D. Use of Rice Hull Ash to Reduce Temperature in High-Strength Mass Concrete. ACI Journal, v. 75, n. 7, p. 60-63, 1978.

MEHTA, P. K.; PITT, N. Energy and Industrial Materials from Crop Residues. Resource

Recovery and Conservation, v. 2, p. 23-28, 1976.

NEHDI, M.; DUQUETTE, J.; EL DAMATTY, A. Performance of Rice Husk Ash Produced Using a New Technology as a Mineral Admixture in Concrete. Cement and Concrete Research, v. 33, n. 5, p. 1203-1210, 2003.
RAVERDY, M. et al. Appréciation de l'Activité Pouzzolanique de Constituents Secondaires. In: CONGRÉS INTERNATIONAL DE LA CHIMIE DES CIMENTS, 7., Paris, 1980. Anais... Paris, 1980. v. 3, p. 36-41.

SEDRAN, T.; DE LARRARD, F. Betonlab Pro2, Computer-Aided Mix-Design Software Pub. 2000. École Nationale des Ponts et Chaussées. Disponível em: <http://www.lcpc.fr/LCPC/Bottin/Organigramme/ TGCE/formulation/pagebetonlabpro.htm>. Acesso em: 16 jun. 2008.

SUGITA, S. On the Burning Principle and the Furnace Design Based on the Principle for Producing Highly Active Rice Husk Ash. In: INTERNATIONAL CONFERENCE ON THE CONCRETE FUTURE, 3., Kuala Lumpur, 1994. Anais... Kuala Lumpur, 1994. p. 215-220.

WALLER, V. Relations Entre Compositions des Betons Exothermie en Cours de Prise et Resistance en Compression. 1999. 297 f. Tese (Spécialité Structures et Matériaux) - École Nationale dês Ponts et Chaussées, Paris, 1999.

ZHANG, M.-H.; MALHOTRA, M. HighPerformance Concrete Incorporating Rice Husk Ash as a Supplementary Cementing Material. ACI Materials Journal, v. 93, n. 6, p. 629-636, 1996.

\section{Agradecimentos}

À Capes, ao CNPq e à Faperj, pelo auxílio financeiro. 